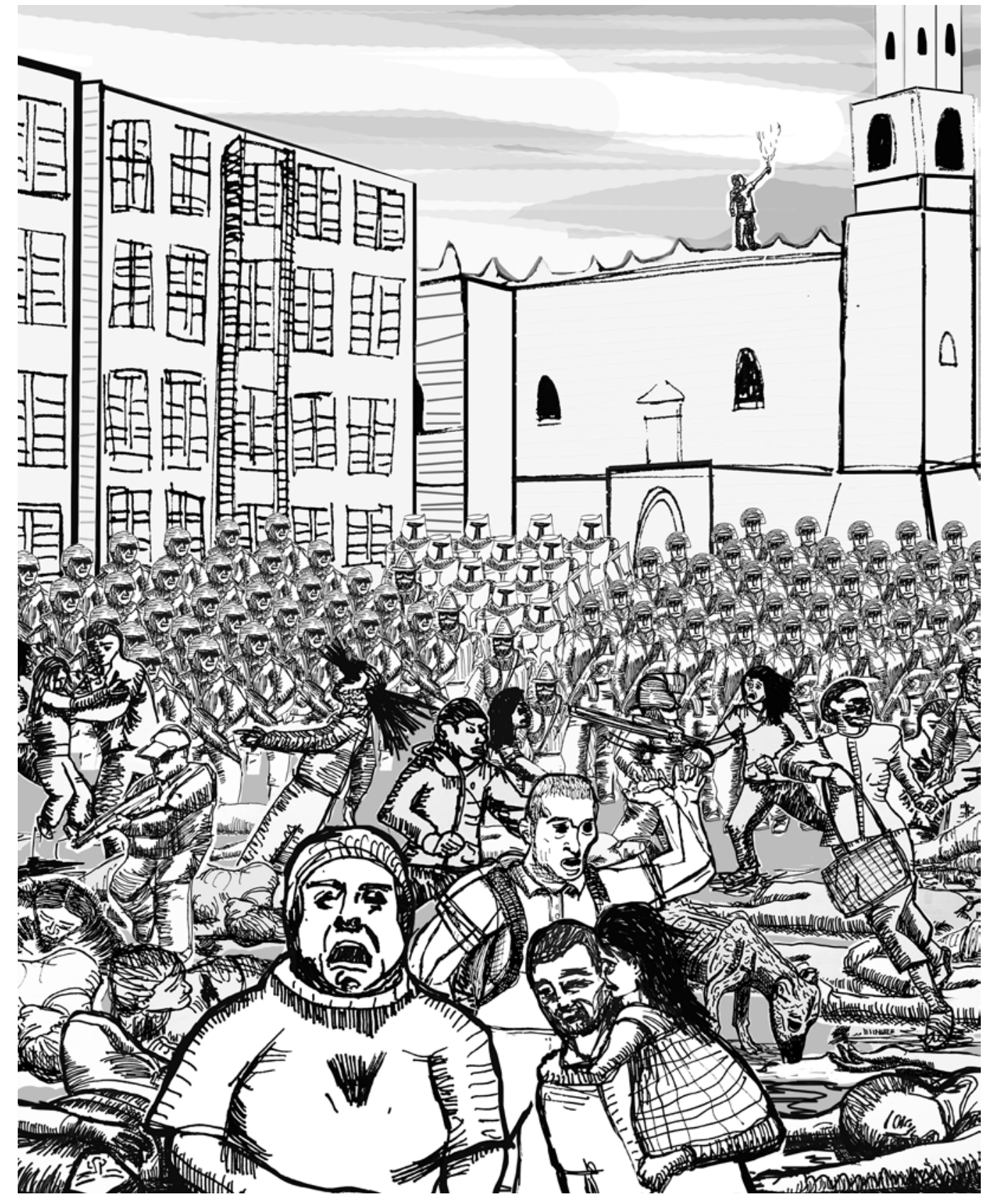

Carolina G. Alpízar

Sin título

Ilustración digital 2017 


\section{Relación de la tristísima destrucción de Indias}

Alfonso Chase Brenes

$R$

elación de la tristísima destrucción de Indias, es un largo poema escrito entre 1968 y 1969. Editado en revistas y antologías pero nunca publicado en libro o editado en Costa Rica.

Historia coloquial en poemas. Ruptura. Retrato y crónica de días y tiempos difíciles. Rumor y purulencia de sucesos que se repiten desde el origen mismo de la vida. Rizoma escondido, árbol y llave secreta. Formarán parte del libro Cántigas de escarnio, para editar por la Editorial Arboleda, en el año 2016.

\section{LLAVE DE FUNDACIÓN}

Y tomaban cuanto a su alcance veían: collares, pectorales, frutas, mancebos y mujeres, porque diezmados por el hambre o el horror ellos se dejaban tomar. Agobiados por el peso del botín algunos invasores se ahogaron al cruzar los ríos y en el fondo de los canales, entre escombros, los niños jugaban con los cuerpos y los huesos de los que fueron sus padres.

Setenta y cinco días duró el asedio.

Durante todo ese tiempo

Aprendimos a beber la sangre de nuestros hijos para lograr subsistir y cuando la ciudad al fin se rindió, abrimos todas las puertas y tendidos, la boca contra el suelo, pedimos la peste para nuestros cuerpos.

Y luego fue la dispersión.

El rumor de aguas llenando los oídos y los pájaros mosdisqueando los ojos y los días cayendo como flechas entre los caminos.

Y no teníamos comida o escudos o armas y la ciudad empezó a podrirse, tal una fruta, y los gusanos nacieron de nuestras bocas, senos y cabellos.

Doquier fue soledad y lluvia y sangre y luego el cal y canto cercando edificios, rincones, templos, hasta volvernos a todos a la vida, como nacidos de un sueño ligero en el deslumbramiento del día.

\section{PALABRAS PARA UN PRÍNCIPE}

Mira que no te acuerdes

de cosa carnal alguna.

Que tu cuerpo un árbol sea

$\mathrm{y}$ en tu alma viva el aire

y se establezcan los pájaros.

Que te reconozcas en el pensamiento

y en el ánimo humilde

y no respondas palabra dura o golpees con tu bastón a los ancianos. Allégate a los sabios, a las poetas y a los niños. 


\section{FIESTAS}

Para los primeros días mataban

a muchos niños.

Para las calendas cada cuerpo

era la historia

de una lejana sucesión de rostros

$y$ en el momento de la muerte

se cumplía algún solsticio.

No los crucificaban, ni los colgaban

entre dos ladrones, sino que los extendían

sobre la piedra dura

y luego comían los corazones.

Por la tarde repartían los muslos

y los brazos

y los sexos

entre el pueblo.

De noche, los muros herían

y la costra oscura de la sangre

atraía moscas y perros

y sonaban los gritos

y sobre todos los rostros

estallaba la fiesta amarilla de la luna.

\section{SORDO REPOSO}

El pecho le brillaba

untado de aceites y bálsamos.

Caminaba seguido de ocho pajes

y en las últimas noches retozaba

con cuatro doncellas.

Era alto y meláncolico

como si se supiera embalsamado

en sus propias palabras.

Durante trescientos sesenta y cuatro días

vagó por las calles

cegado por su propia belleza

y no fornicaba

absorto en la contemplación

de sus manos.

El día del sacrificio

Subió las escaleras con dignidad

y en la muerte

tuvo el oficio

que da la guerra continua con la vida.

Del sabor de su corazón dice este poema

y la suave memoria de su desnudo cuerpo

fue obstinación de pensamiento,

por largos días,

en algunas muchachas

y muchachos.

\section{QUE SON PUERTAS}

Charcos de sangre y de palabras.

Palabras muertas y palabras vivas

nos alacanzan,

nos pisan los talones, nos escupen

sus gritos y disputan entre sí.

Los ojos de todas las palabras. Sueltos sobre la mesa. Luchando pro mirarnos, por romper el silencio y ser testigos de alguna devastación obstinada.

El agua del canal hierve en palabras.

Sobre sí mismas se arrojan.

Se devoran como perros

y entre babas, aullando,

se destrozan en el suelo.

Pero no temas. Las palabras

guardan sus armas en los dinteles.

Se dispersan como ordenadas huestes

de soldados vencidos

y se pierden, menudas y sonámbulas, por entre puertas abiertas.

\section{¿1532?: 1968}

No dejaron caer bombas de napalm, no envenenaron las aguas,

ni sembraron los campos de minas y no pusieron trampas en los jardines.

Los códices se estuvieron silencionsos

y lo periodistas

reseñaron que no teníamos miseria, ni explosión demográfica, y que la tierra era compartida en común y no teníamos gases lacrimógenos

o celdas especiales de tortura.

No hubo diarios que informaran

de nuestro llanto

ni teletipos que transmitieran 
nuestros gritos.

Ningún compañero empapeló

con proclamas

el vacío de los muros

ni desde los balcones

los francotiradores

hicieron blanco en los yelmos.

Ellos siguieron tomando nuestras tierras

$\mathrm{y}$ vendiendo a nuestros niños

y el silencio fue el único camino

para nuestros pasos.

No hubo tableteo de ametralladoras

o golpes con bastones eléctricos.

Y bebieron mezcal en vez de Coca Cola

y masticando peyote en lugar de chiclets

y celebraron gozosos la caída de la ciudad y la pudrición de sus habitantes.

\section{PEQUEÑA HISTORIA}

Toda la noche

escuchó la voz de su hermano

entre las piedras y canales.

Toda la noche batalló con las palabras

hasta hartarse de horror

con el sonido de su propio nombre.

Tres veces cerró la puerta de piedra

de su recámara

y otras tantas el viento la empujó

y lo encontró desnudo y ebrio

entre las mantas.

$\mathrm{Al}$ amanecer hizo encender braceros

y quiso que el incienso lo llenara todo, hasta que los niños se ahogaran.

Por la tarde se lavó,

fornicó e hizo fiesta

por la muerte de su hermano

$\mathrm{y}$ de su amigo Tzicquiatzin

y los dos mil ochocientos guerreros

que iban a sitiarle.

\section{BATALLA FLORIDA}

Donde el agua sin armas

de los dedos

expande nombres y arcabuses.
Donde lo apenas vivido

es contemplado

en su áspera destrucción

por atrapar los pasos

y penosas palabras se levantan

y son puentes.

Donde las flores,

Se están quietas. Donde lo limpio ofende

y la historia es solo un nombre

encarnado en el instante próximo

que se estalla en sonajas, códices

y pasos.

Y a pesar de los crímenes,

los sacrificios y las guerras,

una piedra y otra piedra se levantan

para construir

el rostro de todos.

\section{ÚLTIMO ESTAR}

Volcado sobre sí mismo como un río, pasa los días girando, leyendo textos

y evitando la cercanía de la carne.

Modera su enojo. Corta puentes

y establece trampas en los ventanales

y esconde las armas

y desesperado mira a las estrellas.

Incendios hubo adentro de su sangre

y murió de una pedrada,

como un perro.

De tantos signos adversos,

de tanta traición

y tanto mierda,

ahíto de astrólogos y sueños,

con la cabeza colgada, vacío de su propia sangre,

su cuerpo estuvo muchos días con sus noches

tendido en los mercados

y el agua temblaba

en todos los canales

y el miedo

picoteaba lo ojos

y los labios

de las gentes. 


\section{SUEÑO CUMPLIDO}

Los soldados apartan la neblina con sus ametralladoras y cumplen en las calles su oficio de insectos. Lavan raíces. Limpian muros $\mathrm{y}$ raspan piedras con sus cepillos de acero. En la ciudad: ¿México, Bogotá, Caracas?, Los niños salen a la calle de nuevo $\mathrm{y}$ tienen miedo de recibir el sol en sus ojos y los perros lamen la sangre de los estudiantes.

Luis, Guillermo, Jack y yo

caminamos entre huesos

y purulencias y destrucción

de días ceremoniosos y carcomidos

como si fuera 1535 ,

pero en 1968 resulta inútil

hablar de antiguas fiestas o navíos

cuando nos queda entre las manos solo un lenguaje de rifles y de gritos.

Tlatelolco, 1968

Bogotá, 1969 